Ege Tıp Dergisi / Ege Journal of Medicine 2021; 60 (3): 230-235

\title{
Pulmoner emboli vakalarında AngioJet yardımı ile yapılan reolitik farmako- mekanik trombektomi uygulamalarında anestezi deneyimimiz
}

\section{Our anesthesia experience in reolytic pharmaco-mechanical thrombectomy performed by AngioJet in pulmonary embolism cases}

Gökhan İnangil (iD

Sağlık Bilimleri Üniversitesi Sultan Abdülhamid Han Eğitim Araştırma Hastanesi, Anestezi ve Reanimasyon Servisi, İstanbul, Türkiye

Öz

Amaç: Bu çalışmada pulmoner emboli endikasyonu ile reolitik trombektomi uygulanan olgulardaki erken dönem anestezi deneyimlerimizi sunmayı amaçladık.

Gereç ve Yöntem: Eylül 2016-Mayıs 2018 tarihleri arasında pulmoner emboli tanısı ile hibrit ameliyathanede AngioJet reolitik trombektomi uygulanan 25 hasta retrospektif olarak incelendi. Hastaların demografik verileri, ameliyat sırasında ve sonrasında gelişen komplikasyonlar değerlendirildi.

Bulgular: AngioJet yardımı ile reolitik trombektomi uygulanan toplam 25 hastada (11 erkek, 14 kadın; ort. yaş $61,4 \pm 14,9$ yıl; dağılım 22-83 yıl) lokal anestezi ile birlikte sedasyon uygulamalasının tercih edildiği görüldü. İşlem esnasında bradikardi ve öksürük sık olarak karşımıza çıkan yan etkiler olarak belirlendi. İki hastamızda öksürük sonrası hemoptizi gelişti. Hasta pozisyonuna veya anesteziye bağı komplikasyon gelişmedi.

Sonuç: Gelişen yeni cerrahi ve perkütan girişimsel tekniklere paralel olarak anestezi uzmanları da uygun anestezi planı ve yönetim stratejisi oluşturmalıdır. Perkütan temelli girişimsel yöntemlerin, özellikle hibrit ameliyathanelerde ve kardiyak anestezi prensipleri uygulanarak yakın monitörizasyon ile izlenmesi gerektirmektedir. Bununla beraber oluşabilecek komplikasyonlar ve acil cerrahi embolektomi intiyacı oluşabileceği akılda tutulmalıdır.

Anahtar Sözcükler: Anestezi, trombektomi, pulmoner emboli.

\section{ABSTRACT}

Aim: This study aims to present our early anesthetic experiences in patients undergoing AngioJet rheolytic thrombectomy for the treatment of pulmonary embolism.

Materials and Methods: Twenty-five patients who underwent AngioJet rheolytic thrombectomy in the hybrid operating room with the diagnosis of pulmonary embolism between September 2016 - May 2018 were retrospectively analyzed. Demographic data of the patients and complications that developed during and after the procedure were evaluated.

Results: It was observed that local anesthesia with sedation was preferred in 25 patients $(11$ males, 14 females; mean age $61.4 \pm 14.9$ years; range 22 to 83 years) who underwent rheolytic thrombectomy with the assistance of AngioJet. During the procedure, bradycardia and cough were frequently identified side effects. Hemoptysis developed after cough in two of our patients. No complications developed related with patient position or anesthesia.

\footnotetext{
Sorumlu yazar: Gökhan İnangil

Sağlık Bilimleri Üniversitesi Sultan Abdülhamid Han Eğitim

Araştırma Hastanesi, Anestezi ve Reanimasyon Servisi,

İstanbul, Türkiye

E-posta: ginangil2@gmail.com

Başvuru tarihi: 12.08.2020 Kabul tarihi: 31.01.2021
} 
Conclusion: In parallel with the new surgical and percutaneous angiographic techniques, anesthesiologists should also develop an appropriate anesthesia plan and management strategy. Percutaneous-based interventional methods should take place in hybrid operating theaters and require the implementation of cardiac anesthesia principles with close monitoring. However, it should be kept in mind that there may be complications and the need for urgent surgical embolectomy.

Keywords: Anesthesia, thrombectomy, pulmonary embolism.

\section{GíRiş}

Akut pulmoner emboli (PE), pulmoner arterin veya dallarının pıhtı, tümör, yağ veya hava gibi herhangi bir nedenle tıkanması olarak tanımlanır ve kardiyovasküler ölümlerin inme ve kalp krizinden sonraki en sık üçüncü sebebidir $(1,2)$. Sıklıkla derin bacak venlerinden köken alır ve $50 \%$ oranında asemptomatik seyredebilir (1). Spesifik olmayan kliniği ve teşhiste ideal bir biyobelirtecin bulunmaması nedeniyle tanısı zor bir hastalıktır (2). Cerrahi immobilizasyon, yatak istirahati, hormon ve steroid tedavisi, gebelik, oral kontraseptif kullanımı, geçirilmiş inme, malign hastalıklar, PE için risk faktörleridir $(3,4)$.

Akut PE tedavisinde, medikal tedavi yanında cerrahi ve perkütan kateter aracılığı ile tedavi seçenekleri de mevcuttur. Bu amaçla özel kateterler ile trombotik tedavi veya ultrasonik endovasküler sistem ile trombolitik ajanlar kullanılabilir $(4,5)$. Perkütan kateter temelli girişimlerin amacı, hızlı bir şekilde pulmoner arter basıncı, sağ ventrikül yüklenmesi ve pulmoner vasküler direnci azaltmak ve perfüzyonu arttırmaktır. Özellikle sistemik trombotik tedavinin kontrendike olduğu durumlarda masif ve submasif $P E$ tanılı hastalarda trombüs yükünü azaltarak hayat kurtarıcı olmaktadır (6).

Günümüzde birçok farklı cihaz trombektomi amacı ile kullanılmaktadır. Bu cihazlar başııca damar duvarına temas eden ve etmeyen olarak iki ana grupta sınıflandırılabilir. Damar duvarına temas eden cihazlar etkili olmakla beraber sıklıkla belirgin bir damar travması ile birliktedir. Ayrıca parçalanan ve büyüklükleri $3 \mathrm{~mm}$ 'yi bulan trombolitik materyalin intravasküler tahliyesine bir çözüm getirememişlerdir. Bu nedenle distal embolizasyon potansiyeli taşırlar $(7,8)$. Diğer bir grup mekanik trombektomi cihazları ise direk damar duvarına temas etmezler ve pıhtıyı parçalamak için basınçlı salin veya trombolitik ajan kullanılır. $\mathrm{Bu}$ yüksek basınçlı akımın proksimalinde Venturi etkisi olarak adlandırılan vakum fenomeni oluşur ve parçalanan trotik materyal kateter aracılığı ile tahliye edilir (9). Bu işlem reolitik trombolizis olarak tanımlanır ve
AngioJet (Boston Scientific, Marlborough, USA) en sık kullanılan ve çalışılan kateterdir $(8,9)$.

Perkütan temelli girişimlerin uygulandığı hastalar, sıklıkla hemodinamik açıdan instabil ve solunum sıkıntısı olan kişilerdir. İşlem esnasında gelişebilecek komplikasyonlar da göz önüne alındığında, işlemin gerektiğinde mekanik ventilasyon uygulabilecek anestezi ekibi eşliğinde yapılması kaçınılmazdır. $\mathrm{Bu}$ yazıda hibrit ameliyathanemizde uygulanan perkütan reolitik trombektomi işleminde erken dönem anestezi deneyimimizi sunmayı amaçladık.

\section{GEREÇ ve YÖNTEM}

Sağlık Bilimleri Üniversitesi Hamidiye Girişimsel Olmayan Etik Kurul (Karar no: 2018/0746418926-050.03.04) onayı sonrası Eylül 2016 Mayıs 2018 tarihleri arasında pulmoner emboli tanısı konulan ve trombolitik tedavinin kontrendike olduğu, hibrit ameliyathanede AngioJet ile reolitik trombektomi uygulanan 25 hastanın intraoperatif anestezi kayıtları, operasyon notları ve hastane kayıtları retrospektif olarak incelendi.

Klinik protokolümüze göre AngioJet ile reolitik trombektomi uygulanacak hastalara, işlem öncesi $10-15 \mathrm{ml} / \mathrm{kg}$ kristaloid solüsyonla hidrasyon uygulanmaktadır. Supin pozisyoda maske ile 5 It/dk oksijen başlanan hastalar standart olarak 5 kanal elektrokardiyogram (EKG), periferik oksijen satürasyonu $\left(\mathrm{SpO}_{2}\right)$ ve sağ radiyal arter kanülasyonu ile invazif olarak arteriyal kan basıncı mönitörize edilmektedir. İki adet geniş lümenli periferik damar yolu açılmakta ve tüm hastalara işlem başlangıcında intravenöz 5000 ünite heparin standart olarak yapılmaktadır. Lokal anestezi ile birlikte sedasyon altında gerçekleştirilen bu girişimlerde sedasyon sıklıkla 2-3 mg midazolam ve 50-100 $\mu \mathrm{g}$ fentanil ile sağlanır. Ramsey Sedasyon Skalası 2 düzeyi hedeflenerek gerekli durumlarda fentanil ve midazolam ek dozlarıyla sedasyon derinliği elde edilir.

İşlem sırasında ise; geçici olarak değerlendirilen (kılavuz telin veya kateterin konumlanması 
esnasında oluşan) ve hemodinamiyi bozmayan bradikardi ve aritmilere müdahale edilmezken, derin bradikardi ve atriyoventriküler (AV) blok durumlarında atropin 0,5-1 mg intravenöz olarak uygulanmaktadır. İşlem esnasında ve öncesinde hipotansiyon varsa öncelikle sıvı replasmanı, yanıt alınamaması durumunda noradrenalin 1-3 $\mu \mathrm{g} / \mathrm{kg} / \mathrm{dk}$ dozlarında infüzyon başlanmakta, anlık gelişen hipotansiyon durumlarında efedrin 5-10 $\mu \mathrm{g}$ bolus, hipertansiyon gelişmesi durumunda ise öncelikle sedasyon derinliği kontrol edilerek gerekli durumlarda gliseril trinitrat bolus yapılmaktadır. Dirençli hipertansiyon durumlarında ise $1-5 \mu \mathrm{g} / \mathrm{kg} / \mathrm{dk}$ dozunda klinik yanıta göre gliseril trinitrat infüzyonu başlanmaktadır. İşlem sonrası hastalar monitörize şekilde yoğun bakım ünitesine transfer edilmekte ve gelişebilecek komplikasyonlar açısından 12-18 saat izlenmektedir.

$\mathrm{Bu}$ retrospektif çalışmada, hastaların işlem esnasındaki bradikardi, aritmi gibi işleme veya anesteziye bağlı gelişen komplikasyonlar anestezi izlem formları incelenerek, işlem sonrası gelişen komplikasyonlar ise hasta dosyalarının incelenmesi sonucu çalışma formuna kaydedildi.

\section{BULGULAR}

Toplam 25 hastanın dosyası incelendi. Hastaların 14'ü kadın (\%56) ve 11 erkek (\%44) idi. Ortalama yaş; $61,4 \pm 14,9$ yıl; dağılım 22-83 yıl idi. Yapılan değerlendirmede 9 hasta (\%36) ASA II, 16 hasta (\%64) ASA III olarak belirlendi. Hastaların preoperatif değerlendirmesinde ortalama sağ ventrikül çapı $47,4 \pm 8,4 \mathrm{~mm}$, ortalama pulmoner arter basınçlarının ise $51,8 \pm 11,4 \mathrm{mmHg}$ olarak ölçüldüğü tespit edildi. Hastaların preoperatif ortalama periferik oksijen satürasyonunun ise $\% 86,6 \pm 4,6$ olduğu görüldü.

Hastaların 8'inde (\%32) malignite öyküsünün olduğu, 13'ünde (\%52) bilateral pulmoner arterin etkilendiği, $15^{\prime}$ ine $(\% 60)$ ise derin ven trombozunun (DVT) eşlik ettiği görüldü. Hastaların işlem öncesi tamamında dispne, 13 'ünde (\%52) göğüs ağrısı, 10'unda (\%40) ise ritm bozukluğu tespit edildi ve ortalama şikayet süresi $6,8 \pm 5$ gün olarak hesaplandı.

AngioJet cihazının çalışması ile 8 hastada (\%32) hemodinamiyi bozmayan aritmi gerçekleşirken 2 hastada (\%8) hemodinamiyi bozan ventriküler taşikardi (VT) nedeni ile işleme ara verildi. Elektriksel kardiyoversiyon intiyacı olmadığı görüldü. İşlem esnasında $3 \quad(\% 12)$ hastada atropin uygulamasına intiyaç duyulan AV blok izlendiği bununla beraber hiçbir hastada asistoli gözlenmediği tespit edildi.

Anjiografi aşamasında $11 \quad(\% 44)$ hastada radyokontrast ajan verilmesiyle, 12 (\%48) hastada ise AngioJet cihazı çalışırken öksürük geliştiği görüldü. Toplam 2 (\%8) hastada işlem esnasında öksürük sonrası hemoptizi geliştiği belirlendi. Hastaların hiçbirinde işlem sırasında kardiyak arrest ve entübasyon intiyacı olmadığı ancak bir vakada reolitik trombektomi kateteri çalışırken öksürüğe bağlı desatürasyon geliştiği ve işlem tamamlanana kadar maske ile kısa süreli pozitif basınçlı maske ventilasyonu uygulandığı tespit edildi. İşlem esnasında karşılaşılan komplikasyonlar ve insidanslar Tablo-1'de gösterilmiştir.

İşlem sonrası yoğun bakıma transfer edilen hastalardan 2'inde (\%8) akut böbrek yetmezliği (ABY) gelişirken, sadece 1 hastada (\%4) akut tübüler nekroza bağlı oligüri nedeniyle diyaliz gereksinimi olduğu görüldü. ABY gelişen 2 hastanın preoperatif üre ve kreatinin değerleri normal sınırda iken postoperatif takiplerinde kreatinin seviyesinin 1,5 kat üzerinde arttığı tespit edildi. Yine yoğun bakım izlemi sırasında 9 hastada (\%36) hematüri geliştiği görüldü. Klinik takip esnasında durumu kötüleşen 2 hastanın (\%8) entübe edilerek mekanik ventilatöre bağlandığı belirlendi. Hastaların 10'unda (40\%) ise işlem sırasında ve sonrasında herhangi bir komplikasyonun gelişmediği görüldü.

Tablo-1. AngioJet reolitik trombektomi işlemi esnasında karşılaşılan komplikasyonlar.

\begin{tabular}{lll}
\hline \multicolumn{1}{c}{ Komplikasyonlar } & İnsidans \\
\hline Öksürük & $\begin{array}{l}\text { Kontrast ajan } \\
\text { enjeksiyonu ile } \\
\end{array}$ & $11(44 \%)$ \\
& AngioJet çalışırken & $12(48 \%)$ \\
Aritmi & $\begin{array}{l}\text { Reolitik trombektomi } \\
\text { esnasında bradikardi }\end{array}$ & $8(32 \%)$ \\
& $\begin{array}{l}\text { / AV Blok } \\
\text { Atropin uygulanan } \\
\text { bradikardi / AV Blok }\end{array}$ & $3(12) \%$ \\
& Ventriküler taşikardi & $2(8 \%)$ \\
Hemoptizi & & $2(8 \%)$ \\
Desatürasyon & & $1(4 \%)$ \\
\hline
\end{tabular}

"Veriler sayı ve yüzde olarak belirtilmiştir (\%) 


\section{TARTIŞMA}

Günümüzde, Avrupa ve Amerika yönergeleri $P E$ ile başvuran hastaları başlangıç klinik sunumuna ve hemodinamik duruma göre çeşitli kategorilere ayırmıştır. Buna göre, yüksek riskli veya masif $\mathrm{PE}$, sistolik hipotansiyon (sistolik kan basıncı $<90$ $\mathrm{mmHg}$ ) veya bazal sistolik kan basıncının> 40 $\mathrm{mmHg}$ düşmesi veya inotropik destek gerektiren hemodinamik instabilite olarak sınıflandırır (10). Tedavi yöntemleri tek başına antikoagülasyondan sistemik intravenöz tromboliz ve beraberinde perkütan veya cerrahi trombektomiye kadar değişebilmektedir (11-13).

Kateter embolektomisi, submasif akut pulmoner embolisi olup klinik olarak kötü prognoz bulguları (yeni oluşan hemodinamik instabilite, ilerleyen solunum yetmezliği, ciddi sağ ventrikül disfonksiyonu veya majör miyokardiyal nekroz) olan hastalar için göz önünde bulundurulabilir. Kateter embolektomi ve cerrahi trombektomi, düşük riskli $P E$ veya submasif akut $P E$, minör sağ ventrikül disfonksiyonu, minör miyokardiyal nekroz ve klinik olarak stabil hastalar için önerilmemektedir (12).

AngioJet'in önemli bir teknik özelliği kateter ucundan, 2500 psi kadar yüksek basınçlı heparinize salin ile jet akımı sağlaması ve damar duvarına zarar vermeden trombüsü parçalanmasıdır $(7,14)$. Bu yüksek basınçlı akım Venturi etkisi ile geriye doğru yüksek basınçlı 360 derecelik vakum oluşturur ve trombüs parçalarını ve debrisi daha proksimaldeki bir lümenden tahliye eder. Salin akış hızı, kateter kalınlığına göre 40-60 mL/dk arasında değişir. Trombüs parçaları ve debris emilerek akış hızına uygun olarak kateterden tahliye torbasına drene olur. AngioJet kateterleri boyutları $60-140 \mathrm{~cm}$ uzunluğunda ve 4F-6F çaplarında değişmektedir ve 2-12 mm çaplı damarlarda kullanılabilmektedir (8). Bu sistemin avantajı, dönen hareketli bir komponenti olmadığından damar duvarına zararın minimal olmasıdır (15).

Ancak yüksek basınç gradiyentinin hemolize sebep olduğu düşünülmektedir. Intravasküler hemoliz, AngioJet kullanımında görülen ve adenozin salınımına bağlı bradiaritmiler gibi kardiyak komplikasyonların sebebidir. Artmış hemoliz sıklıkla uzamış trombektomi zamanı ile birliktedir. Diğer yanda güçlü emiş gücü nedeni ile trombüsün uzaklaştırılma hızı artar iken kan kaybı da artmaktadır (9).

AngioJet cihazının kullanıldığı mekanik trombektomi ile ilişkili bradikardi, koroner damarlarda iyi tanımlanmış bir fenomendir. Intrakoroner AngioJetin kullanımını inceleyen sınırı hayvan çalışmaları birçok olası mekanizma ileri sürmüş fakat bradikardi fenomeninin tam etiolojisini ortaya koymada yetersiz kalmıştır. Trombektomi ile serbestleşen hemoliz ürünleri nedeni ile atrioventriküler nodda ileti gecikmelerine sebep olması, sol ventrikülde non miyelinize gerilime duyarlı reseptörlerin aktivasyonu ve siklik yüksek basınç gradiyentinin, sağ kalbin refraktör osilasyon sistemi üzerine direkt etkisi gibi mekanizmalar ileri sürülmüştür (16). Bradiaritmik fenomen için birçok hipotez ileri sürülse de en akla yakın olanı bradikinin ve adenozin gibi masif nörohormonal maddelerin hemolize sekonder salınımına bağlı ortaya çıkışıdır (17). Bununla beraber deneyimlerden gözlendiği kadar reolitik trombektomi (RT) kateterinin durdurulması bradikardiyi hemen sonlandırmaktadır (18). Yine RT süresinin ve RT kateterinin kalbe yakınlığının, bradikardi başta olmak üzere aritmilere daha sık yol açtığı belirtilmektedir (19). Dolayısı ile birden fazla mekanizmanın bu durumda rol oynadığı düşünülebilir. RT kateterininin çalışmasına bağlı gelişen bradikardik fenomen koroner damarlarda \%20-79 olarak rapor edilirken, pulmoner trombektomi esnasında \%12-20 olarak bildirilmiştir(18). Bizim olgularımızda bu oran $\% 32$ olarak gerçekleşti ve \%12 olguda atropin ile müdahale gereksinimi oldu. Bradikardiyi engelleme ve azaltmada tedavi stratejileri aminofilin, glikopirolat veya atropin uygulaması ve geçici pace uygulamasını içerir $(20,21)$. Vakalarımızda invazif arteriyel tansiyon monitörize edildiğinden hemodinamiyi bozmayan bradikardi durumlarında işlemin aşaması ve zamanlaması göz önünde bulundurularak atropin uygulaması kontrollü olarak yapıldı. Dirençli durumlarda RT kateterinin durdurulması istendi. AngioJet'in periferal venlerde kullanılması bile bradikardiyi tetiklemektedir. Ancak pulmoner arterde kullanımında bu etki daha fazla olmaktadır. Bradikardi oluşmadan hastaların işlem öncesi aminofilin ve atropin uygulaması tavsiye edilmemektedir (16). Bununla beraber hastalara rutin olarak eksternal defibrilatör pedlerinin işlem öncesi yapıştırıması kardiyak hastalıkları ve bradikardi ve asistoli epizodunu tolere edemeyecek hastalarda önerilebilir.

Hemolizle ilişkili diğer endişeler hiperkalemi ve hemoglobinüridir. Hiperkalemi elektriksel instabiliteyi şiddetlendirebilirken hemoglobinüri sınırda böbrek fonksiyonları olan hastalarda böbrek fonksiyonlarını daha da kötüleştirebilir. Kontrast maddenin kullanımı da bu hastalar için yine ayrı bir risktir $(14,22)$. Önceden var olan böbrek yetmezliği, kullanılan radyoopak 
maddenin volümü ve kontrast madde seçimi gibi birçok faktör nefrotoksisite gelişiminde rol oynar (23).

Kontrast maddelerin yan etkilerinin iyi bilinmekle beraber, düşük osmalariteye sahip non iyonik ajanlar nefrotoksisite ve aşırı duyarlılık reaksiyonları açısından daha az riske sahiptir (23-25). Kontrast maddelere karşı aşırı duyarlılık reaksiyonları idiosinkratik ve non-idiosinkratik olarak ikiye ayrılır. İdiosinkratik reaksiyonlar doz bağımlı değildir ve anaflaktoid tabiattadır (bronkospazm, ürtiker, kaşıntı, peritibial ödem) ciddi idiosinkratik reaksiyonlar oldukça nadir olup hızlı ve fokal pulmoner arteriyel enjeksiyona bağlıdır (26). Non idiosinkratik reaksiyonlar volum bağımlı ve kontrastın kemotoksik ve hiperosmolar özelliklerinin bir sonucudur. Non idiosinkratik reaksiyonlar göz önünde bulundurulduğunda düşük osmolar non-iyonik ajanların en önde gelen avantajı öksürük insidansını azaltmasıdır (23, 24, 26). İşlem esnasında loheksol (Omnipaque $350 \mathrm{mg} / 50 \mathrm{ml}$, Opakim, Türkiye) 1:1 oranında dilüe edilerek kullanıldı. Buna rağmen işlem esnasında muhtemelen bronkospazma bağlı gelişen öksürük insidansımız \%44 idi. Bu durumda desatürasyon gelişen vakalar olduğu gibi öksürük sonrası hemoptizi nadir olmakla beraber uyanık hastada problem oluşturabileceği göz önünde tutulmalıdır.

Kardiyak disritmiler pulmoner anjiografi sırasında kateter manüplasyonu sırasında oluşabilir. Kateterin sağ kalpten pasajı esnansında triküspit kapağın mekanik stimülasyonu atrial fibrilasyon, flatter ve taşikardi oluşturarak atrial ekstrasistol veya taşikardi oluşabilir. Birçok vakada bu durum geçicidir ve kateter manipülasyonu durdurularak sonlandırılabilir. Devam eden atrial flatter ve fibrilasyon durumlarında $\beta$ adrenerjik blokörler kullanılabilir (24).

Kateterin triküspit valvden geçerken duvara teması ile dal bloğu, bradikardi, 2. derece AV Kaynaklar blok veya tam AV blok gelişebilir. Sağ ventrikül duvarına kateterin temas etmesi ise ventriküler ekstrasistole bazen de ventiküler taşikardiye sebep olabilir. Sebat eden ventriküler taşikardi durumlarında 200-400 j ile elektriksel kardiyoversiyon endikedir (24). Olgularımızda kateterizasyon aşamasında sıklıkla hemodinamiyi etkilemeyen disritmiler ile karşılaştık ancak anestezi formlarında kısa süreli ve hemodinamiyi bozmadığından müdahale edilmemiş bu tür olayların tam insidansını ve ayırımını ortaya koyamadık. En sık gözlenen disritmiler ise AngioJet trombektomi kateterinin çalışması ile ortaya çıkan bradikardi ve geçici AV blok (\%24) idi. ancak bu olguların sadece \%50'sine atropin ile müdahaleye intiyaç duyuldu. Yine nadir olmakla beraber işleme ara vermeyi gerektiren ventriküler taşikardi (\%8) gözlendi. Hiçbir hastada asistoli gelişmedi ve elektriksel kardiyoversiyona intiyaç duyulmadı.

\section{SONUÇ}

Gelişen yeni cerrahi ve peruktan girişimsel tekniklere paralel olarak, anestezi uzmanları da uygun anestezi planı ve yönetim stratejisi oluşturmalıdır. Perkütan temelli girişimsel yöntemlerin uygulandığı hastalarda özellikle hibrit ameliyathanelerde kardiyak anestezi prensiplerinin uygulanması ve yakın monitörizasyon ile izlem gerekir. Girişim sırasında komplikasyonların gelişebileceği ve acil cerrahi embolektomi ihtiyacı olabileceği de akılda tutulmalıdır.

Çıkar Çatışması: Çalışmamızda herhangi bir çıkar çatışması bulunmamaktadır.

Teşekkür: Olguların takibi esnasında özveri ile çalışan anestezi teknisyeni Ömer Temel'e ve Kalp ve Damar Cerrahisi Kliniği çalışanlarına teşekkürlerimi sunarım.

1. Essien E-O, Rali P, Mathai SC. Pulmonary Embolism. Med Clin North Am. 2019; 103 (3): 549-64.

2. Çelik M, Avci A, Karataş R, et al. Akut Pulmoner Emboli'de Galectin-3. Bozok Tıp Derg. $2020 ; 9$ (1): $75-82$.

3. Gündüz C; Erdinç M. Dispnenin pulmoner nedenlerine yaklaşım. Ege Tıp Derg. 2014; 53 (Suppl): 7-13.

4. Er CZ, Atılgan K, Demirdaş E. Kronik Derin Ven Trombozu Olan Hastada Akut Gelişen İliyak Ven Trombozunun Farmokomekanik Tedavisi: Olgu Sunumu. Bozok Tıp Derg. 2018; 8 (3): 136-8.

5. Acar E, Yılmaz MF, Barutçu S, et al. Yan ağrısı olan bir hastada renal embolinin perkütan tedavisi. Ege Tıp Derg. 2016; 55 (4): 196-8.

6. Taşolar H, Taşolar S, Pakdemir H. Akut pulmoner emboli tedavisinde perkütan girişimsel tekniklere güncel yaklaşım. Bozok Tıp Derg. 2013; 2 (3): 50-7.

7. Schmittling ZC, Hodgson KJ. Thrombolysis and mechanical thrombectomy for arterial disease. Surg Clin North Am. 2004; 84 (5): 1237-66. 
8. Ierardi AM, Xhepa G, Piffaretti G, et al. Clinical experience with Angiojet: a comprehensive review. Int Angiol. 2015; 34 (6 Suppl 1): 1-14.

9. Blackwood S, Dietzek AM. Pharmacomechanical thrombectomy: 2015 update. Expert Rev Cardiovasc Ther. 2016; 14 (4): 463-75.

10. Ferrigno $\mathrm{L}$, Bloch $\mathrm{R}$, Threlkeld $\mathrm{J}$, et al. Management of pulmonary embolism with rheolytic thrombectomy. Can Respir J. 2011; 18 (4): e52-8.

11. Kucher N, Rossi E, De Rosa M, et al. Massive pulmonary embolism. Circulation. 2006; 113 (4): 577-82.

12. Jaff MR, McMurtry MS, Archer SL, et al. Management of massive and submassive pulmonary embolism, iliofemoral deep vein thrombosis, and chronic thromboembolic pulmonary hypertension: a scientific statement from the American Heart Association. Circulation. 2011;123 (16): 1788-830.

13. Konstantinides S V, Meyer G, Becattini C, et al. 2019 ESC Guidelines for the diagnosis and management of acute pulmonary embolism developed in collaboration with the European Respiratory Society (ERS). Eur Heart J. 2020; 41 (4): 543-603.

14. Bonvini RF, Righini M, Roffi M. Angiojet Rheolytic Thrombectomy in Massive Pulmonary Embolism: Locally Efficacious but Systemically Deleterious? J Vasc Interv Radiol. 2010; 21 (11): 1774-6.

15. Biederer J, Schoene A, Reuter M, et al. Suspected pulmonary artery disruption after transvenous pulmonary embolectomy using a hydrodynamic thrombectomy device: clinical case and experimental study on porcine lung explants. J Endovasc Ther. 2003; 10 (1): 99-110.

16. Jeyabalan G, Saba S, Baril DT, et al. Bradyarrhythmias during rheolytic pharmacomechanical thrombectomy for deep vein thrombosis. J Endovasc Ther. 2010; 17: 416-22.

17. Karnabatidis D, Katsanos K, Kagadis GC, et al. Re: Bradyarrhythmias during use of the angiojet system. J Vasc Interv Radiol. 2007; 18 (7): 937-8.

18. Zhu DWX. The potential mechanisms of bradyarrhythmias associated with AngioJet thrombectomy. J Invasive Cardiol. 2008; 20 (8 Suppl A): 2A-4A.

19. Antoniucci D. Management of dysrhythmias during coronary AngioJet: how to minimize the need for temporary pacemaker during rheolytic thrombectomy. J Invasive Cardiol. 2008; 20 (8 Suppl A): 22A-4A.

20. Fontaine AB, Borsa JJ, Hoffer EK, et al. Type III heart block with peripheral use of the Angiojet thrombectomy system. J Vasc Interv Radiol. 2001; 12 (10): 1223-5.

21. DeLago A, El-Hajjar M, Kirnus M. Aminophylline for prevention of bradyarrhythmias induced by rheolytic thrombectomy. J Invasive Cardiol. 2008; 20 (8 Suppl A): 9A-11A.

22. Dukkipati R, Yang EH, Adler S, et al. Acute kidney injury caused by intravascular hemolysis after mechanical thrombectomy. Nat Clin Pract Nephrol. 2009; 5 (2): 112-6.

23. Saeed M, Braun SD, Cohan RH, et al. Pulmonary angiography with iopamidol: patient comfort, image quality, and hemodynamics. Radiology. 1987; 165 (2): 345-9.

24. van Loveren $M$, van Beek EJR, Oudkerk M. Pulmonary Angiography: Technique, Indications and Complications. In: van Beek EJR, Büller HR, Oudkerk M (eds) Deep Vein Thrombosis and Pulmonary Embolism. Chichester, UK: John Wiley \& Sons, Ltd; 2009: 221-46.

25. Nilsson T, Carlsson A, Mâre K. Pulmonary angiography: a safe procedure with modern contrast media and technique. Eur Radiol. 1998; 8 (1): 86-9.

26. Smith DC, Lois JF, Gomes AS, Maloney MD, Yahiku PY. Pulmonary arteriography: comparison of cough stimulation effects of diatrizoate and ioxaglate. Radiology. 1987; 162 (3): 617-8. 